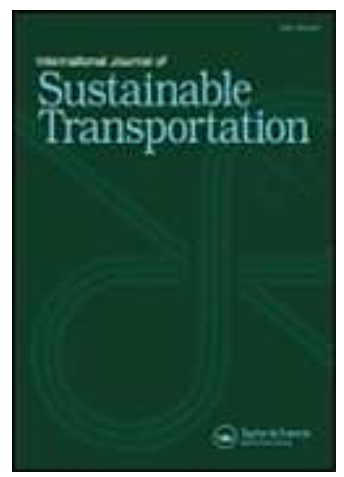

\title{
PERSONAL TRANSPORT EMISSIONS WITHIN LONDON: EXPLORING POLICY SCENARIOS AND CARBON REDUCTIONS UP TO 2050
}

\begin{tabular}{|c|c|}
\hline Journal: & International Journal of Sustainable Transportation \\
\hline Manuscript ID: & UJST-2009-0047.R1 \\
\hline Manuscript Type: & Full Paper \\
\hline $\begin{array}{r}\text { Date Submitted by the } \\
\text { Author: }\end{array}$ & 12-Apr-2010 \\
\hline Complete List of Authors: & $\begin{array}{l}\text { Harwatt, Helen; University of Leeds, Institute for Transport Studies } \\
\text { Tight, Miles; University of Leeds, Institute for Transport Studies } \\
\text { Timms, Paul; University of Leeds, Institute for Transport Studies }\end{array}$ \\
\hline Keywords: & Transport, Carbon emissions, Policy \\
\hline
\end{tabular}

\section{今 scholarONE" \\ Manuscript Central}


PERSONAL TRANSPORT EMISSIONS WITHIN LONDON:

EXPLORING POLICY SCENARIOS AND CARBON REDUCTIONS UP TO 2050

\author{
Helen Harwatt \\ Institute for Transport Studies, University of Leeds, UK. \\ Miles Tight* \\ Institute for Transport Studies, University of Leeds, UK. \\ Paul Timms \\ Institute for Transport Studies, University of Leeds, UK. \\ *Corresponding author
}




\title{
PERSONAL TRANSPORT EMISSIONS WITHIN LONDON: EXPLORING POLICY SCENARIOS AND CARBON REDUCTIONS UP TO 2050
}

\begin{abstract}
This research explored the possibility of achieving significant carbon reductions from personal land-based transport using London as a case study. A profile of carbon emissions from personal land-based transport modes was derived using Great Britain National Travel Survey (NTS) data and a range of carbon emissions factors. A carbon calculator provided carbon consumption per trip. NTS survey data were grossed up to national level using Census of Population data. A baseline of carbon emissions, based on equal per capita consumption, was projected to 2050 using estimates of future population. Four future scenarios were developed and tested using this data. These were: (a) based on the London Mayor's Climate Change Action Plan; (b) a technology focussed scenario; (c) a personal carbon trading scenario; and (d) a radical walking and cycling scenario. Results suggest that the latter two scenarios have the potential to achieve emissions reductions in excess of $80 \%$, whilst scenarios (a) and (b) are somewhat weaker, though still achieve substantial reductions in carbon emissions compared to business as usual.
\end{abstract}

\section{INTRODUCTION}

Transport is currently responsible for around a quarter of the UK's total anthropogenic Carbon Dioxide $\left(\mathrm{CO}_{2}\right)$ emissions and this proportion is projected to increase. The transport sector will undoubtedly need to play a significant role in achieving carbon reductions if the Government is to meet its $80 \%$ legally binding carbon reduction target by 2050 , as set out in the 2008 Climate Change Bill (OPSI, 2008). One of the biggest challenges is how to translate 
national carbon reduction policy to a more local level, particularly in terms of the best way to implement policies at a city level in order to bring about real change. Urban areas are both concentrations of climate vulnerability as well as major consumers of carbon (Dawson et al, 2007), while the concentration of activity in such relatively small areas gives a high potential for the development of innovative solutions, perhaps more so than elsewhere.

London provides the focus for this research which ultimately aims to deliver a unique insight into the role that cities play in generating carbon emissions. This paper is focussed on carbon emissions from personal land-based transport and seeks to identify the most effective policy instruments which could be used to reduce carbon emissions by 2050 in line with the date set for many national and international agreements on greenhouse gas reductions. The GLA (2007) estimate that ground based transport emissions in London could increase by around $22 \%$ by 2025 reflecting population and employment growth in a "business as usual" scenario. It is unclear to what extent this baseline includes current government measures to reduce transport carbon emissions outlined in the UK climate change programme which imply stabilisation by 2020 (DEFRA, 2006; DTI, 2007).

The paper explains first the method and approach to calculating carbon emissions in section 2 and then provides estimates of carbon emissions for 2004 and looking forward to 2050 in section 3. Finally section 4 explores the impact of 4 different future scenarios and their likely effect on carbon emissions from personal transport.

\section{ESTIMATING CARBON EMISSIONS FROM PERSONAL TRANSPORT WITHIN LONDON}

This research explored the potential for use of travel diary style information as a means to estimate carbon emissions from land-based personal transport. Whilst the focus of this research was London, the method developed could equally be applied to other areas of 
Britain, elsewhere if appropriate travel information were available or to an organisation if data were available on associated travel.

\subsection{Data sources}

Two key sources of travel diary information exist which provide information about personal travel associated with London: The National Travel Survey (NTS) and the London Area Transport Survey (LATS). The NTS is nationally representative and carried out annually for the Department for Transport (DfT) and is completed using interviews, questionnaires and travel diaries in households across Great Britain (Hayllar et al, 2005). The total sample size in the data set used (2004) was 8122 households. The data that are available from the main report of the survey (DfT, 2005) includes mode and purpose of travel, trip distance, origin and destination area type, travelling time, vehicle and household information.

The LATS, published through the London Travel Report (TfL, 2005), focuses specifically on the travel behaviour of London residents and tourists to the city. There are various data included in the output of this report, however perhaps the most relevant in relation to this research is that of trips made between areas of London (central, inner and outer), and modes used.

For this research, the travel data collected in the NTS were used as this includes all travel by households throughout the country thus allowing an estimation of the proportion of trips made within London by households outside of London and hence London's personal transport 'footprint'. 2004 data on journeys, stage, households, individuals and vehicles were used in this research ${ }^{1}$.

\footnotetext{
${ }^{1}$ It is worth noting that due to the nature of the NTS data this research does not take account of travel as part of business activities, travel by overseas non-resident visitors or traffic passing through London (as the NTS data only provides journey origin and destination - though given the focus on Greater
} 


\subsection{Allocating personal travel to London}

An early task was to define the boundaries of Greater London and the travel and emissions which are associated with it. This is particularly an issue when dealing with a discrete geographical region, which has considerable links with the area outside and is especially important when investigating London given the array of economic activity taking place, its size, and the number of visitors it attracts. The allocation of transport emissions to London could follow a number of approaches, for example, to examine emissions just from households or consumers residing in London or to examine all trips generated by London regardless of their origin. For this study, it was concluded that emissions arising from all parts of trips that occur within London from all GB residents should be included. Hence, trips wholly within the Greater London boundary, parts of trips within London which start within and end elsewhere and parts of trips within London which start from outside but end within would all be included. This approach gives a good overview of the carbon footprint of the city and is also compatible with undertaking a similar process for other contiguous areas without resulting in double-counting of emissions.

Trips that start or end in London are easily identified from the NTS data by the journey origin and destination variables, which are provided only at the level of Government Office Region (GOR) due to sample size and thus representivity issues. The distance for trips starting in London but ending elsewhere, and starting elsewhere and ending in London was adjusted to estimate the element of travel undertaken within the London boundary. The average straight line distance from the centre of London to the boundary was estimated to be $22.5 \mathrm{~km}$. Thus, for trips which began in London and ended elsewhere (in another GOR), or began elsewhere and ended in London, the within London distance was set at $22.5 \mathrm{~km}$ if it was originally more

London and the exclusion of most of the M25 orbital motorway from the study area this is believed to be relatively minor). 
than or equal to $45 \mathrm{~km}$. If the total trip distance was originally less than $45 \mathrm{~km}$, the London distance was assumed to be half of the total distance. Figure 1 illustrates the study area and the journeys which were included. Trips wholly within the London boundary were left unaltered and actual recorded distances were used.

Figure 1 about here

\subsection{Deriving carbon emissions from the NTS sample data}

The calculation of carbon emissions per trip was derived using an existing carbon calculator tool which is described more fully in Bristow et al (2004). This requires information regarding the carbon emissions per kilometre per mode, average journey speed, trip occupancy and trip distance.

Carbon emissions factors for cars and vans were derived using data produced by DEFRA (2007). The data provides carbon emissions for petrol and diesel vehicles with engine sizes of less then 1.4 litres, 1.4 to 2.0 litres and above 2 litres. These data were used alongside data from SMMT (2006) which provided change in vehicle efficiency over time, thus allowing emissions factors for car and van to be estimated based on vehicle age, fuel type and engine size. Merging the NTS journey data with the NTS vehicle data provided details of the household vehicle used on each journey. Where a non-household vehicle was used or where vehicle data were missing, an average emissions factor was used for car and van weighted on the proportion of petrol and diesel vehicles licensed in 2004. The emissions factors were also weighted based on journey speed, for example all speeds less than $35 \mathrm{mph}$ were classed as urban, speeds of $35-50 \mathrm{mph}$ were classed as rural, and speeds above $50 \mathrm{mph}$ were classed as motorway travel. The urban emissions factor was used to derive the rural and motorway emissions factors - for petrol vehicles it is multiplied by 1.16 for motorway speeds and 0.84 for rural speeds. For diesel the figures are 0.87 and 0.72 respectively (NAEI, 2007). The 
carbon emissions factors for bus were based on occupancy rates from Transport for London service performance data as reported in the Mayor's Climate Change Action Plan (GLA, 2007), being 15 in 2004. For bus trips made outside of London, an average occupancy of 9.2 was assumed. The carbon emissions for bus were also weighted to reflect urban, rural and motorway journey speeds. Tube, light rail and rail figures were derived from the Mayor's Climate Change Action Plan (GLA, 2007), with DEFRA (2007) providing the same figures for rail.

Carbon emissions factors were allocated to each trip based on the mode of transport used (taking into account vehicle age, engine size and fuel type for household owned vehicles) and the average journey speed. The carbon emissions per trip were then calculated by multiplying the emissions factor by journey distance and dividing by the number of people on the trip (for car, van and taxi only), thus avoiding double counting of trips. Air transport was omitted due to the small sample of such trips in the 2004 NTS data.

\subsection{Creating baseline carbon emissions for London}

After travel within London had been identified from the NTS data and carbon emissions per trip had been calculated, the average kilometres, trips and carbon per person per mode were derived for each NS-SEC in each GOR, which is the lowest level of geographical disaggregation possible within the NTS data (excluding London where a further disaggregation into inner and outer is possible in the 2004 dataset). Two additional groups were added to represent the proportion of the population under the age of 16 years and over the age of 74 years (these groups are not covered by the NS-SEC which covers working age population only but are included in the NTS and Census data). These data were then used to create a baseline of carbon emissions for London by grossing up to population data from the 2001 census, split by NS-SEC, under 16's, over 74's and GOR. 


\section{KEY RESULTS}

\subsection{Carbon emissions for London in 2004}

All personal land-based transport within London produced an estimated 1.14 million tonnes of carbon in the baseline year (2004). This includes all personal travel within the geographical boundaries of Greater London from all households in Great Britain (GB). Table 1 provides 3 sets of figures for comparison: firstly total carbon associated with all trips involving London residents; secondly all carbon associated with trips which have at least an element in London; and finally carbon emitted only within the boundary of London.

\section{Table 1 about here}

For inner London residents it is estimated that the majority of their carbon use results from trips related to London, i.e. either starting and ending in London; starting in London and ending elsewhere (in another GOR), or starting elsewhere (in another GOR) and ending in London. However, after removing the carbon associated with the part of their journeys outside of London shows that inner Londoners consume $70 \%$ of their carbon within London and the remainder in non-London GOR's. For outer London residents only $50 \%$ of their total carbon is actually emitted within London. The data suggests that outer London residents conduct more of their activities in areas outside of the Greater London boundary than those from inner London. This is logical given the closer proximity of outer London residents to the London boundary in comparison to inner London residents. In addition, the travel survey data shows that outer London residents typically have greater access to personal motorised transport (TfL, 2005), whereas inner London residents do a larger proportion of their trips using public transport. 
The following results consider carbon emitted within the boundaries of the Greater London area, with figure 2 showing the proportion of carbon emitted in London by travellers' area of residence (GOR).

Figure 2 about here

Half of all personal transport emissions produced in 2004 in London were generated by outer London residents, with inner London residents contributing roughly the same amount as nonLondon residents who travel within London. Car use was responsible for the majority of carbon from all areas, with outer London having the largest proportion (74\%) and inner London having the lowest proportion (55\%). In terms of carbon from public transport, inner London had the highest proportion $(41 \%)$ with other non-London areas having the lowest proportion (19\%), followed closely by outer London (20\%). Figure 3 shows carbon per person emitted within London for different GOR's.

\section{Figure 3 about here}

This shows that per head of population inner and outer London account for the majority of carbon emissions in London. Given their respective mode shares, outer Londoners have a higher average carbon use of 29 grams per kilometre travelled (excluding walking and cycling) compared to inner Londoners who produce 24 grams of carbon per kilometre.

Population data from the 2001 census (correlated with the NTS data) were used to estimate the amount of carbon emitted by different employment categories. Figure 4 shows the proportion of carbon used by region for each category (the first 5 categories are from the NSSEC).

Figure 4 about here 
As expected, the data in figure 4 is not reflective of population data where for example in 2001 the largest category was made up of the under 16's (22\%), followed by routine (18\%) and supervisory $(15 \%)$. On a per person basis the figures differ, for example individuals within the management group consume $33 \%$ more carbon compared to those in the supervisory group. Car accounted for the largest proportion of emissions across each category, with the supervisory group having the largest proportion $(73 \%)$ and the nonworking group having the lowest proportion of their emissions from car use (53\%). The management group had the largest proportion of carbon from rail use, with the self-employed group having the least amount of carbon from rail. The management group also had the largest proportion of carbon from tube use, with the under 16's having the smallest proportion of carbon from tube use. The non-working group had the largest proportion of carbon from bus use (followed closely by the under 16's) whilst the management group had the least amount of carbon from bus use. These findings no doubt reflect to some extent mode use by the different groups.

\subsection{Forecasting carbon emissions up to 2050}

Carbon emissions were forecast up to 2050 assuming that each person continues to consume the same amount of carbon each year per mode of transport and trip. The forecast accounted for estimated population increases by GOR up to 2050 (based on information supplied by Dawson et al, 2007). The forecast data includes all personal land based travel within London from households throughout Great Britain. It should be noted that the forecast carbon data does not take into account changes to carbon emissions factors over time and/or modal shift such issues are explored through the policy scenarios in section 4. Figure 5 shows the forecast carbon emissions by mode within London up to 2050. Hence, the business as usual assumptions do not reflect improvements in vehicle energy efficiency which might be expected to occur over such time periods. 
Figure 5 about here

Figure 5 suggests that by 2050 emissions could increase by around $60 \%$ without any policy intervention (though this takes no account of alternative travel choices which may arise from, for example, increasing congestion). In addition to the contribution to greenhouse gas emissions, the growth in traffic volumes and subsequent congestion would make policy intervention essential to avoid such a situation.

\section{POLICY SCENARIOS}

In order to estimate the impact of different potential measures to reduce carbon emissions in London, 4 policy scenarios were developed and tested. For each scenario, the carbon impact was estimated at 5 yearly intervals from 2010 to 2050 . The forecast carbon data shown in figure 5 provided the baseline emissions for use in the scenarios.

Four scenarios are considered, the first based on the London Mayor's Climate Change Action Plan (CCAP) to 2025 and an extension of this to 2050 (termed CCAP+), the second looking particularly at the potential role of the development of new technologies, the third explores the introduction of a carbon trading scheme and finally a fourth looking at a possible large scale lifestyle change with walking and cycling taking on considerably more importance in society as modes of transport than currently. A number of assumptions were made regarding mode share in each scenario. The scenarios are not intended to be prescriptive, rather to represent a varied set of possible alternative futures. Table 2 shows the mode split assumptions made for 2025 and 2050.

\section{Table 2 about here}


Currently within London, car use accounts for $41 \%$ of trips made, public transport accounts for $37 \%$ and walking and cycling together account for $22 \%$ (TfL, 2005). The first two scenarios assume the same modal split both with changes occurring largely as a result of new trips being undertaken by public transport and walking and cycling. The carbon trading scenario sees further reductions in car use by 2050 , whilst the walking and cycling scenario envisages major lifestyle changes in the role of different transport modes within London, where cars are used for essential trips only and walking, cycling and public transport become the norm for most trips. Clearly such a scale of change will also imply a move towards localisation of activities and associated land-use change.

The following sections describe each scenario and their estimated impacts on London's carbon emissions.

\subsection{Scenario 1: The London Mayor's Climate Change Action Plan}

This scenario interprets the carbon savings from full implementation of the Mayor's CCAP (GLA, 2007). This pursues an ambitious target of a $60 \%$ reduction in emissions by 2025 . It contains a mix of aspirational and potentially achievable measures and concludes that a $60 \%$ reduction within this timeframe is probably not achievable. However, reductions from 1990 levels of around $22 \%$ by 2025 to achieve a $4.3 \mathrm{MtC}$ saving across all ground based transport (including business travel, freight and aviation) are thought to be achievable, in the following ways (GLA, 2007):

- Modal shift $20 \%$

- Increased operational efficiency $20 \%$

- $\quad$ Eco-driving (all modes) $10 \%$

- Improved infrastructure and vehicles $35 \%$ 
- Lower carbon fuels $15 \%$.

Interestingly $50 \%$ of these additional savings are estimated to arise from changes in travel behaviour. Figure 6 shows the estimated carbon consumption relative to the 2004 baseline (see figure 5) - it should be noted that whilst the CCAP includes all ground based transport, this research focussed on personal (rather than business) land-based transport excluding aviation and freight.

Figure 6 about here

Due to population growth, emissions continue to grow beyond the baseline until after 2015 when a reduction occurs. By 2025 , the carbon savings amount to an $11.5 \%$ reduction from 2004 levels. Currently the projections in the CCAP do not progress beyond 2025. It is estimated here that, without further action beyond 2025, as a result of forecast population increases (obtained from Dawson et al, 2007) carbon emissions could grow to $3.4 \%$ beyond the 2004 baseline by 2050 . Also shown in figure 6 is a CCAP+ scenario which assumes that further action (i.e. in addition to what is currently contained in the CCAP) is taken post 2025 at least to allow for population growth and maintain a minimum reduction of around $11.5 \%$ from the 2004 baseline. By 2050, CCAP+ would require a $45.8 \%$ reduction from baseline levels (the carbon emissions which would arise in 2050 under population growth alone - see figure 5). In order to achieve such reductions, it is assumed that in addition to the policies contained within the CCAP up to 2025, further travel demand measures would be implemented such as an extension of the congestion charge zone in response to rising traffic levels with the charge per entry linked to vehicular carbon emissions.

\subsection{Scenario 2: Technology}


This scenario builds on the reductions made in scenario 1 thus providing additional carbon cuts by assuming further policy implementation beyond that contained within the Mayor's CCAP and CCAP+. Within this scenario it is assumed that a mandatory agreement exists amongst car manufacturers supplying the UK market in order to achieve regular reductions in carbon use per kilometre driven by passenger cars. In the short term it is expected that internal combustion engines (ICE's) will continue to be the dominant technology in the UK and that car manufacturers who have invested heavily in the next generation of ICE's will want a return on this investment before introducing alternative technologies (King, 2008). In addition, the largest risk to manufacturers occurs at the prototype stage when external funding during the research and development stage has been used, hence manufacturers take significant risks when introducing new technologies to the market, particularly when they are more expensive to the consumer compared to ICE technology (IPPR, 2008) and are thus likely to require an established demand before taking such risks.

The King review (2008) foresees that electric hybrid vehicles will be the main alternative vehicle for the next 25 years. It is also expected that fuel efficiency would become more important in purchasing decisions over time if oil prices rise, hence it is assumed that the majority of motorists would also opt for lower emissions vehicles. As a result, based on technology available and the automotive engineering capabilities in the UK, across the fleet it could be possible to achieve a 30\% carbon reduction per kilometre within the next $5-10$ years, a 50\% carbon reduction per kilometre by 2030 and an $80 \%$ carbon reduction per kilometre by 2050 (King, 2008). It is recognised that as a result of the current global economic recession, the automotive industry in the UK is not necessarily the same as when the assumptions were made by King (2008). The New Automotive Innovation and Growth Team (NAIGT) describe the current industry as being 'fragile' and 'not compelling' and set out a road map for action (NAIGT, 2009), which includes a timeline of uptake for technology such as electric vehicles and plug in hybrids. 
Within the technology scenario it is assumed that the King figures are attainable (the analysis was conducted prior to the current economic recession), however the rate of uptake of lower emissions vehicles has been considered in terms of a lack of a strong policy driver to change consumer choice, which is also a limitation highlighted by King (2008). It is therefore assumed that by 2010, $9 \%$ of the carbon emitted from cars and vans would come from vehicles which are $2 \%$ more efficient than current and by 2050 this would increase to $65 \%$ and $80 \%$ respectively. In addition, by 2050 it is assumed that $25 \%$ of carbon emissions would be offset by zero emissions vehicles (most likely to be fully electric rather than fuel cell). It is thought that this level of uptake (particularly in terms of hybrids and zero emissions vehicles) would not be mirrored in other UK cities and is thus only applicable to London due to the unique conditions regarding traffic congestion levels and average travel speed. In addition, zero emissions vehicles (such as electric) and hybrids (such as petrol electric vehicles) are permitted to enter the congestion charging zone free of charge thus providing additional incentives particularly in light of charge increases as suggested in scenario 1 (electric vehicles are also exempt from parking costs within London). It is also expected that the production costs of alternative fuelled vehicles would decrease as uptake increased, hence making such vehicles more feasible for a greater number of people over time.

In terms of public transport, by 2050 it is assumed that $40 \%$ of carbon emissions from buses would be emitted from hybrid buses whilst $30 \%$ of carbon would be offset by zero emissions buses. It is expected that uptake of alternative technology amongst the bus sector would be much greater in London where public ownership exists in comparison to other UK cities where private ownership dominates. For rail, tube and light rail it is assumed that by 2050 $40 \%$ of their power would be sourced from renewable electricity with zero carbon emissions at the source and for end use. It is thought that fully decarbonised electricity production would be possible in the UK by 2050 (King, 2008), however it is assumed here that, without a strong incentive to drive demand, most of this would be used to power homes and thus meet existing demands rather than fully incorporate demands from other sectors such as transport. The 
estimated changes in carbon emissions (from 2004 baseline) within London are shown in figure 7.

Figure 7 about here

The assumptions regarding uptake of new technology together with the CCAP and CCAP+ amount to a $67.4 \%$ reduction in carbon emissions by 2050 from the 2004 baseline, using the efficiency gains suggested by King (2008). This is a significant saving and overachieves the targets set out in the CCAP but does not achieve more ambitious targets such as an $80 \%$ reduction by 2050 which is in line with the Climate Change Act. Without the CCAP, technology alone is estimated to achieve a $47.5 \%$ reduction by 2050 from 2004 levels. Figure 7 also shows for comparison a separate line making a different set of assumptions on future vehicle efficiency improvements. These are based on the International Energy Agency (IEA) estimates, but are much lower at $50 \%$ worldwide by 2050 (IEA, 2008) compared to $80 \%$ in the UK by 2050 (King, 2008). Whilst it is recognised that the King figures are more applicable for the UK compared to the IEA which are based on global scenarios, the latter shows the sensitivity of the relationship to changes in vehicle efficiency. The IEA assumptions were applied to estimated savings from increased ICE efficiency for cars, zero carbon cars and buses, hybrid buses and zero carbon electricity use for rail, tube and light rail i.e. all were estimated to achieve $37 \%^{2}$ less than the figures estimated using the King (2008) assumptions. Under the IEA assumptions, technology with the CCAP+ achieves a $46.7 \%$ reduction by 2050. Figure 7 shows that, whilst technology clearly has an important role to play, it appears unable as a single measure to achieve for transport the reductions required by the latest national targets.

\subsection{Scenario 3: Carbon trading}

\footnotetext{
${ }^{2}$ The IEA suggest efficiency gains equating to $37 \%$ less than those suggested by King (2008): $50 / 80=$ $0.63=37 \%$ difference.
} 
Within this scenario it is assumed that a national carbon trading scheme is introduced in the UK in order to meet legally binding carbon reduction targets. The same efficiency improvements in ICE's is assumed as for the technology scenario, however the greatest difference in the current scenario is the level of uptake of zero emissions vehicles by consumers and mode shift, as demonstrated in table 2 . In addition, it is assumed that the trading scheme would stimulate eco-driving practices across all modes, regenerative braking on tube, rail and light rail and operational efficiency gains for both public and private transport, thus providing further cuts (this has been estimated in line with the respective cuts outlined in the CCAP). From 2020, plug in hybrids and electric hybrid propulsion is likely to be common, however the challenge is to create a strong market for demand (King, 2008). This is also recognised by the NAIGT (2009) who point out the current lack of any demand-side interventions to accelerate take-up of low carbon technologies. The carbon trading scheme is expected to drive demand for low carbon technology by periodically reducing the amount of carbon available for purchase in the form of fuel. Low carbon fuels and increased energy efficiency would become much more attractive, thus increasing demand and uptake which in turn is expected to lower production costs resulting in further uptake. For example, it is expected that electric vehicles would have replaced $15 \%$ of carbon emissions from cars and vans by 2025 , increasing to $43 \%$ by 2050 . It is predicted that current technological and cost challenges would be overcome due to rising consumer demand and that light weight and high energy lithium based batteries will become available to enable larger ranges (250 miles and beyond) for electrically powered vehicles before a recharge is necessary. Again it is expected that London would see a greater uptake of electric vehicles compared to other UK cities given the benefits when used in highly congested conditions in addition to being exempt from parking charges and the congestion charge currently active in London. It is possible that the monetary savings from avoiding the congestion charge could help to negate any cost disadvantages of electric vehicles. In addition, if charged overnight when the grid is less congested, electricity would be cheaper than petrol (King, 2008). In this scenario it is 
estimated that $57 \%$ of carbon emissions in 2050 will arise from vehicles which are $80 \%$ more fuel efficient compared to current levels.

It is assumed that by $2050,45 \%$ of carbon emissions from buses would have been replaced by zero emissions fuel (either electric vehicles or hydrogen fuel cells, both producing zero carbon emissions at source and end use). The remaining 55\% of carbon emissions would be replaced by hybrid vehicles which emit around 55\% less carbon per kilometre in comparison to current vehicles. For rail, tube and light rail it is assumed that all would be fully electrified by 2050 and that $90 \%$ of the electricity used to power them would be sourced from renewable, zero carbon emissions electricity production. Again it is expected that there would be a higher uptake of electrification amongst public transport within London in comparison to other UK cities, however the introduction of a national carbon trading scheme could narrow the gap considerably in comparison to scenario 2. In addition, Mathiesen et al (2008) conclude that, in relation to integrating transport with energy planning, a $100 \%$ renewable energy transport system is possible but the path towards it contains significant challenges. The estimated carbon reductions are shown in figure 8.

\section{Figure 8 about here}

The increased uptake and demand for low or zero carbon technology together with a modest mode shift from car to public transport makes an $86.2 \%$ carbon reduction achievable by 2050 , when assuming the efficiency gains suggested by King (2008). This goes beyond the $60 \%$ target set out in the Mayor's CCAP and approximates the 70-90\% thought to be necessary in order to avoid going beyond a $2^{\circ}$ Celsius warming and the worst impacts of climate change (Bows et al., 2006; Stern, 2006). Between 2010 and 2015 it is expected that a $30 \%$ improvement in fuel efficiency has been achieved (King, 2008) and a 15\% uptake is driven by tightening of the annual carbon budget in the carbon trading scheme. This is designed early in the period to 2050 given the greater benefits from early reductions in emissions compared to 


\subsection{Scenario 4: Walking and cycling with carbon trading}

Scenario 4 differs significantly to the others in that it involves a vision of a very different society to that which can be observed at present and can be classified as a post-neoliberal society which emphasises cooperation between citizens rather than competition between consumers. In particular, scenario 4 involves a vision in which there is a high level of public participation in planning and general improvements in quality of life, where phenomena such as conspicuous consumption and coerced mobility are seen as things of the past. The vision for London contained in scenario 4 can be seen as a reflection of the global scenario Great Transition: The Promise and Lure of the Times Ahead created by Raskin et al (2002). In terms of the scientific process for constructing scenario 4, this process is somewhat different than the process for constructing scenarios 1 to 3 . Scenario 4 goes much further than the targets contained in the CCAP in terms of walking and cycling levels and carbon emissions reductions. A key element of scenario 4 is that, instead of walking and cycling being seen as marginal modes (as is current practice), they become central to the whole London transport system.

In order to characterise the walking and cycling aspects of scenario 4, it is useful firstly to examine the assumptions about walking and cycling contained in scenario 1 since scenarios 3 
and 4 essentially extend the level of walking and cycling from this point. Targets for walking and cycling given in the CCAP document (GLA, 2007) assume that mode share for walking would increase 22 percent, with more than one million extra trips taking place every day by 2025. For cycling, the CCAP states that the target is to increase cycling trips by more than 400 per cent by 2025 . This could increase the mode share of cycling in London from one per cent now up to five per cent by 2025 , equating to more than one million extra trips every day. A key objective is for walking and cycling, together with public transport, to accommodate projected demand growth of four million additional trips a day to 2025 without an increase in car trips. These targets probably represent the most that can be achieved by statutory authorities on their own, i.e. for greater changes in walking and cycling to occur there would also need to be fundamental changes in society with respect to lifestyles and ways of working, i.e. as contained in scenario 4 .

Within this scenario, the assumptions regarding efficiency gains, uptake of new technology and eco-driving are the same as scenario 3 - the major difference is in the level of modal shift from personal motorised transport to public transport, walking and cycling, as demonstrated in table 2. The resultant carbon outputs are shown in figure 9.

Figure 9 about here

The increase in modal shift results in a $92.4 \%$ carbon reduction by 2050 from 2004 levels when applying the King (2008) efficiency assumptions, achieving a further $6.2 \%$ than scenario 3. Using the IEA efficiency assumptions, this reduces to $76.1 \%$ by 2050 , a further $21.3 \%$ compared to the trading scenario.

\section{CONCLUSIONS AND POLICY IMPLICATIONS}


This research has employed an innovative methodology to firstly derive carbon emissions arising from personal transport use within London and secondly to derive a set of carbon emissions scenarios based on assumptions from the Mayor's CCAP, the recently published King Review, the IEA global scenarios (2008) and thoughts on a potential carbon trading scheme and wholesale lifestyle change to a much more walking and cycling focussed future. The carbon outputs suggest that the CCAP alone will not achieve the savings necessary nor those aimed for in the CCAP - hence, achieving a $60 \%$ reduction would require considerable levels of investment and policy application, far beyond the scope of the current plans up to 2025. In addition, whilst technology alone can achieve significant reductions it is unable to deliver the necessary $80 \%$ reduction. Technology combined with the CCAP+ under maximum efficiency gain assumptions could possibly achieve close to a $67 \%$ reduction, however this is unlikely to be attainable in practice. Instead, a strong motivator is required in order to drive consumer demand for low and zero carbon technology which in turn reduces production costs and encourages further uptake. A carbon trading scheme with strong periodic reduction targets could provide this stimulus. It is possible that a carbon trading scheme alone could achieve the reductions necessary without a need for further policy such as the CCAP and/or regulations for vehicle manufactures, thus it is assumed here that the trading scheme would be introduced as a stand alone measure that could achieve an $86 \%$ reduction under maximum efficiency gain assumptions. However, it would be essential to input adequate investment into infrastructure changes in order to facilitate changes arising from a carbon trading scheme thus the CCAP could resemble an investment plan for infrastructure rather than a plan to reduce carbon emissions per se, with other local authorities producing similar investment plans.

Carbon trading with the addition of large scale lifestyle shift is estimated to deliver a maximum reduction of $92 \%$, making personal land-based carbon emissions within London almost carbon free by 2050. This is approximating an ideal outcome in terms of climate change policy and whilst eliciting significant challenges is theoretically achievable under the 
right circumstances, making the UK world leaders in terms of policy innovation and carbon reductions. It also provides an opportunity to provide leadership in terms of developing prototype markets for low carbon products (NAIGT, 2009). For example, in order to demonstrate political willingness and organisation, the NAIGT (2009) suggest that a permanent joint industry/government automotive council is established to develop, guide and implement a strategic framework for the industry. This would involve, for example, the creation of a transformed business environment in the UK; agreement on technology road maps for low carbon vehicles and fuels; and the development of a stronger supply base through joint research. The NAIGT (2009) devised the Test Bed UK which is essentially a pilot of their suggested technology road map in order to test deployment into the market. This could be a useful strategy for integrating new technology, particularly where there is a lack of coherent demand side policy intervention.

Whilst the paper has focussed on the transport sector, it is recognised that the transition to low carbon mobility must be synchronised with the overall transition to a low carbon economy and thus the whole energy system (Lund and Mathiesen, 2009). For example, the development of low carbon personal and public transport modes must be considered together with the shift to clean electricity generation (NAIGT, 2009). The development of a low carbon transportation system can actually aid the transition to low carbon energy generation, for example Lund and Munster (2006) found that the use of electricity generation for transport increased the optimisation of wind turbines in West Denmark. The ability to consume unused electricity through overnight charging creates a mutually beneficial relationship between electric vehicles and wind power (greatly reducing the need for storage or transfer). In addition, Lund and Kempton (2008) show that vehicle to grid technology will improve the efficiency of the electric power system, lower carbon emissions and improve the integration of wind power. 
Whilst technology clearly has an important role to play in achieving an $80 \%$ carbon reduction, the possibility of stimulating lifestyle changes through the implementation of measures such as a carbon trading scheme have additional benefits that would not necessarily be delivered through technology alone. Whilst the quantitative measurement of such benefits is beyond the scope of the current research, there could be, for example, increased personal mobility through the action of walking and/or cycling contributing to health and wellbeing policies, such as obesity targets. In addition, in terms of costs to society, an increase in physical activity and a coinciding reduction in traffic congestion could result respectively in reduced costs to the National Health Service and the economy in general.

In order to achieve significant carbon reductions, policy measures must move significantly beyond current practice and level of application, as also recognised by Hickman et al (2010). An intense amount of political desire, willingness and leadership are required in addition to public support in order to accomplish a low carbon and sustainable transport system.

\section{ACKNOWLEDGMENTS}

This research was funded by the Tyndall Centre for Climate Change Research and forms part of its Cities research programme. The Tyndall Centre is supported by the Natural and Environmental Research Council, the Engineering and Physical Sciences Research Council and the Economic and Social Research Council. The views expressed are those of the authors alone.

\section{REFERENCES}

Bows, A., Mander, S., Starkey, R., Bleda, M. and Anderson, K (2006) Living within a carbon budget. Report for Friends of the Earth and the Co-operative Bank, July 2006. Available at: http://www.foe.co.uk/resource/reports/living_carbon_budget.pdf 
Bristow, A., Pridmore, A., Tight, M. and May, A. (2004) How can we reduce Carbon emissions from transport? Tyndall Centre Technical Report 15.

Dawson R., Hall J, Barr S, Batty M., Bristow A, Carney S, Evans E.P., Kohler J., Tight M, Walsh C, Ford A, (2007) A blueprint for the integrated assessment of climate change in cities. Tyndall Centre for Climate Change Research, Working Paper 104.

Department of Environment, Food and Rural Affairs (DEFRA) (2006) Climate Change the UK Programme 2006. White Paper Cm 6764. London: Defra.

Department of Environment, Food and Rural Affairs (DEFRA) (2007) Passenger transport emissions factors. Methodology Paper. June 2007. The Stationery Office, London.

Department for Transport (2005) National Travel Survey 2004. The Stationery Office, London.

Department of Trade and Industry (DTI) (2007) Updated energy and carbon emissions projections: The energy white paper. May 2007. The Stationery Office.

Greater London Authority (GLA) (2007) Action today to protect tomorrow. The Mayors Climate Change Action Plan. London, UK.

Hayllar, O., McDonnell, P., Mottau, C. And Salathiel, D. (2005) National Travel Survey 2003 and 2004 - Technical Report. Report for Department for Transport.

Hickman, R. Ashiru, O. and Banister, D (2010) Transport and climate change: Simulating the options for carbon reduction in London. Transport Policy (17), pp.110-125. 
International Energy Agency (2008) Energy technology perspetives 2008: scenarios and strategies to 2050. Organisation of Economic Cooperation and Development.

IPCC (2007) Summary for Policymakers. In Climate change 2007: Mitigation. Contribution of Working group III to the Fourth Assessment Report of the InterGovernmental Panel on Climate Change [B. Metz, O. R. Davidson, P. R. Bosch, R. Dave, L. A. Meyer (eds)], Cambridge University Press, Cambridge, United Kingdom and New York, NY, USA.

Institute for Public Policy Research (IPPR) (2008) Driving down $\mathrm{CO}_{2}$ emissions: using mandatory targets to improve vehicle efficiency. Report. February 2008.

King, J. (2008) The King review of low-carbon cars. Part I: the potential for CO2 reduction. Prepared for HM Treasury. The stationary office, London.

Lund, $\mathrm{H}$. and Munster, E (2006) Integrated transportation and energy sector $\mathrm{CO}_{2}$ emission control strategies. Transport Policy (13),pp.426-433.

Lund, H. and Kempton, W (2008) Integration of renewable energy into the transport and electricity sectors through V2G. Energy Policy (36), pp.3578-3587.

Lund, H. and Mathiesen, B.V (2009) energy systems analysis of $100 \%$ renewable energy systems - the case of Denmark in years 2030 and 2050. Energy (34),pp.524-531.

Mathiesen, B.V. Lund, H. and Norgaard, P (2008) Integrated transport and renewable energy systems. Utilities Policy (16), pp.107-116.

National Atmospheric Emission Inventory (NAEI) (2007) Road transport emissions factors. 
New Automotive Innovation and Growth Team (NAIGT) (2009) An Independent Report on the Future of the Automotive Industry in the UK. Report to BERR.

Office of Public Sector Information (OPSI) (2008) Climate Change Act 2008. Chapter 27: carbon target and budgeting. Available at:

http://www.opsi.gov.uk/acts/acts2008/pdf/ukpga_20080027_en.pdf

Raskin, P., Banuri, T., Gallopin, G., Gutman, P., Hammond, A., Kates, R., and Swart, R. (2002)

Great Transition: The Promise and Lure of the Times Ahead. http://www.gsg.org/gsgpub.html

Society of Motor Manufacturers and Traders (2006) SMMT annual $\mathrm{CO}_{2}$ report 2005 market.

Stern N. (2006) Stern Review: the economics of climate change. Report to HM Treasury.

Transport for London (TfL) (2005) London Travel Report 2005. Mayor of London. 
Figure 1: Diagram of Greater London showing how carbon emissions for some typical trips were adjusted - adapted from City of London boundaries map (www.cityoflondon.gov.uk).

Figure 2: Carbon emitted within London in 2004 by travellers area of residence (other non-London includes all other GORs in Britain)

Figure 3: Carbon emitted within London in 2004 per person by area of residence

Figure 4: Proportion of Carbon from personal land-based transport emitted within London per year for different employment categories

Figure 5: Estimated carbon emissions (million tonnes) within London up to 2050.

Figure 6: Estimated impact of the CCAP and CCAP+ on carbon emissions from personal land-based transport within London.

Figure 7: Technology \& CCAP+ scenario 2 - estimated reduction in land-based personal transport carbon emissions within London from 2004 baseline.

Figure 8: Carbon trading scenario 3 - estimated reduction in land-based personal transport carbon emissions within London from 2004 baseline.

Figure 9: Trading with walking and cycling scenario 4 - estimated reduction in landbased personal transport carbon emissions within London from 2004 baseline.

Table 1: Kilogrammes of carbon per person per week: London residents 
Table 2: Estimated mode share (\% trips) in 2025 and 2050 for each scenario. 


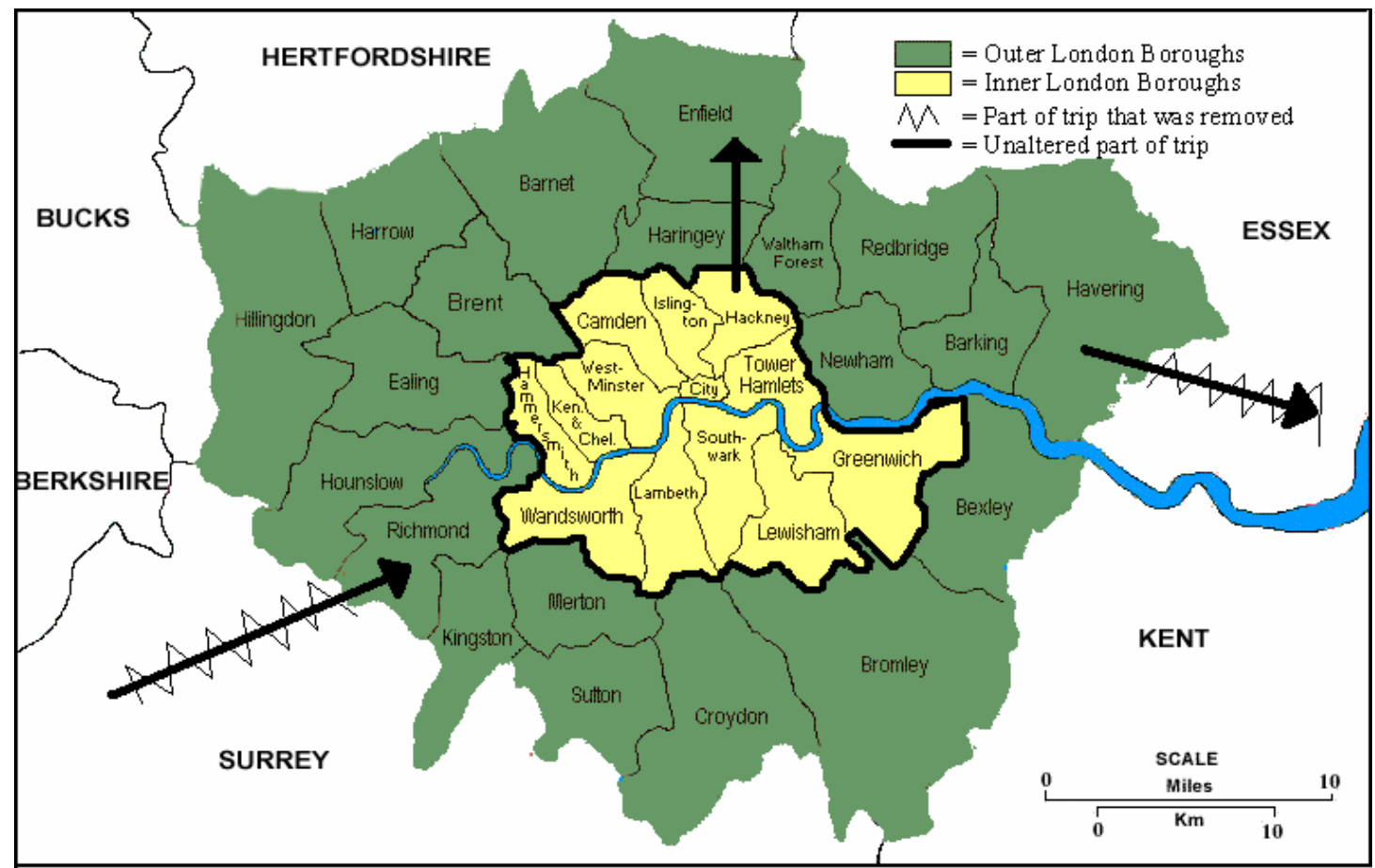

Figure 1: Diagram of Greater London showing how carbon emissions for some typical trips were adjusted - adapted from City of London boundaries map (www.cityoflondon.gov.uk). 


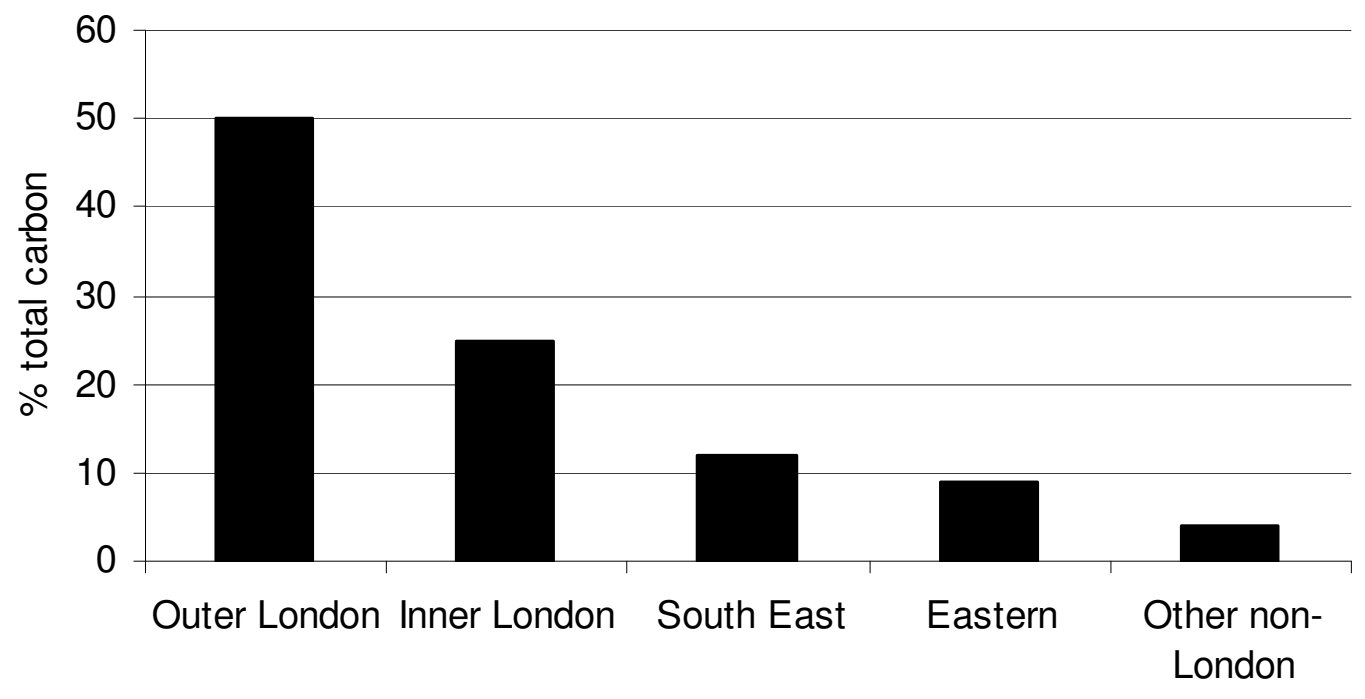

Figure 2: Carbon emitted within London in 2004 by travellers area of residence (other non-London includes all other GORs in Britain) 


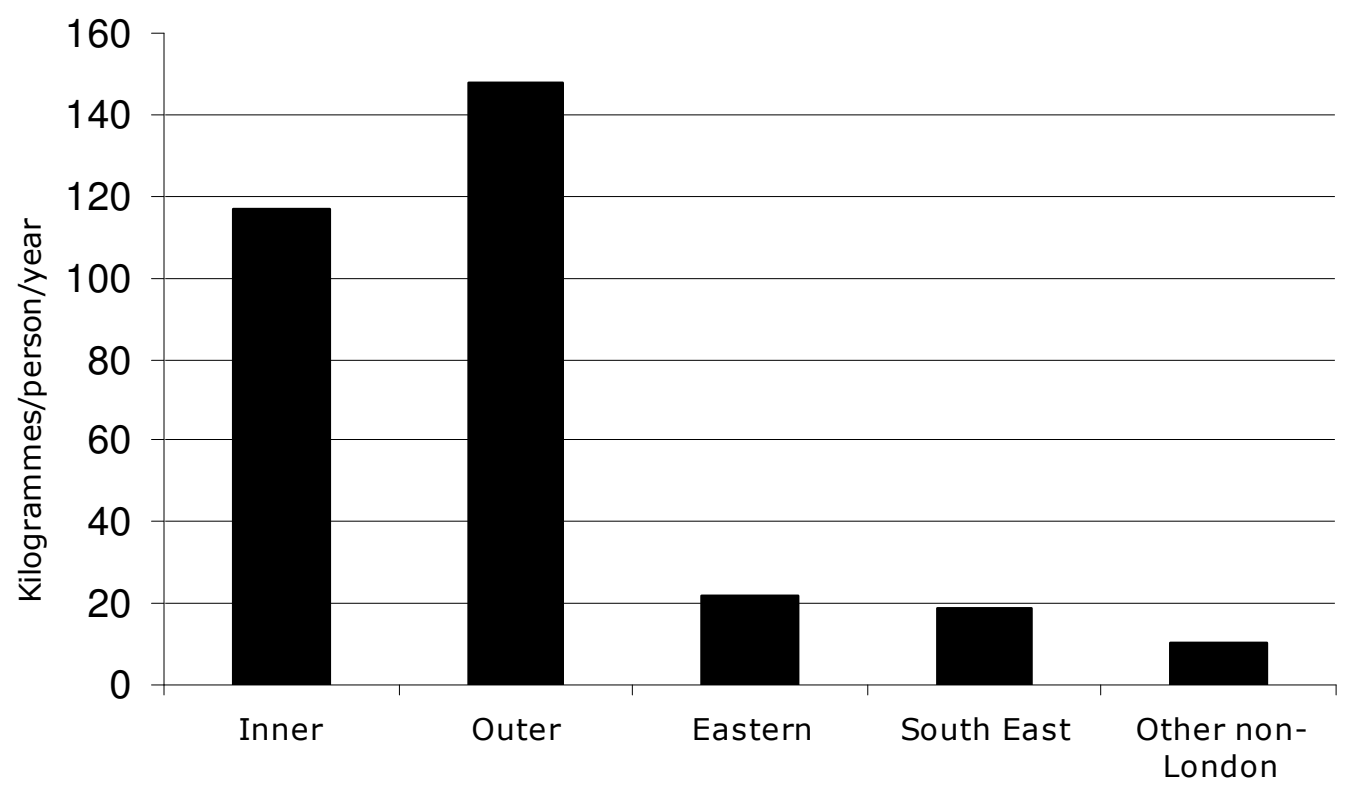

Figure 3: Carbon emitted within London in 2004 per person by area of residence 


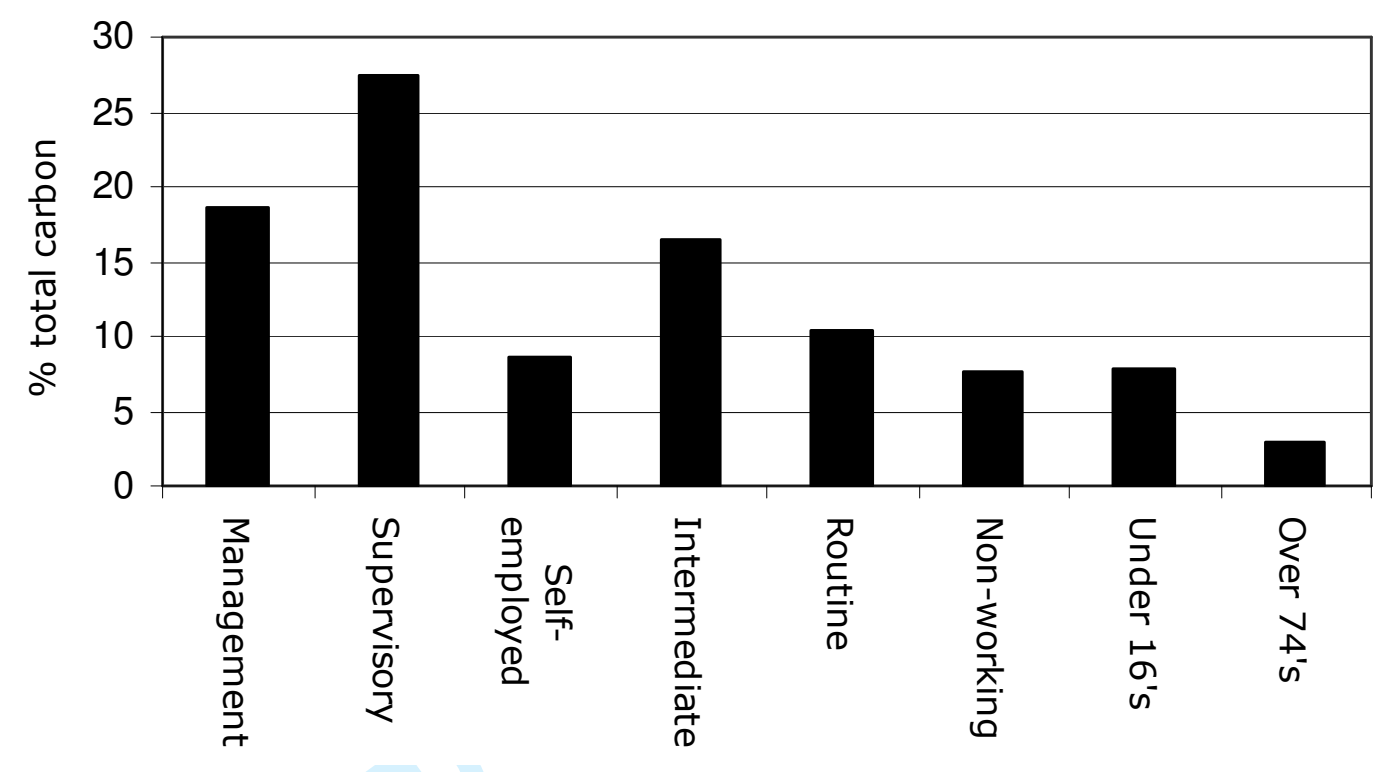

Figure 4: Proportion of Carbon from personal land-based transport emitted within London per year for different employment categories 


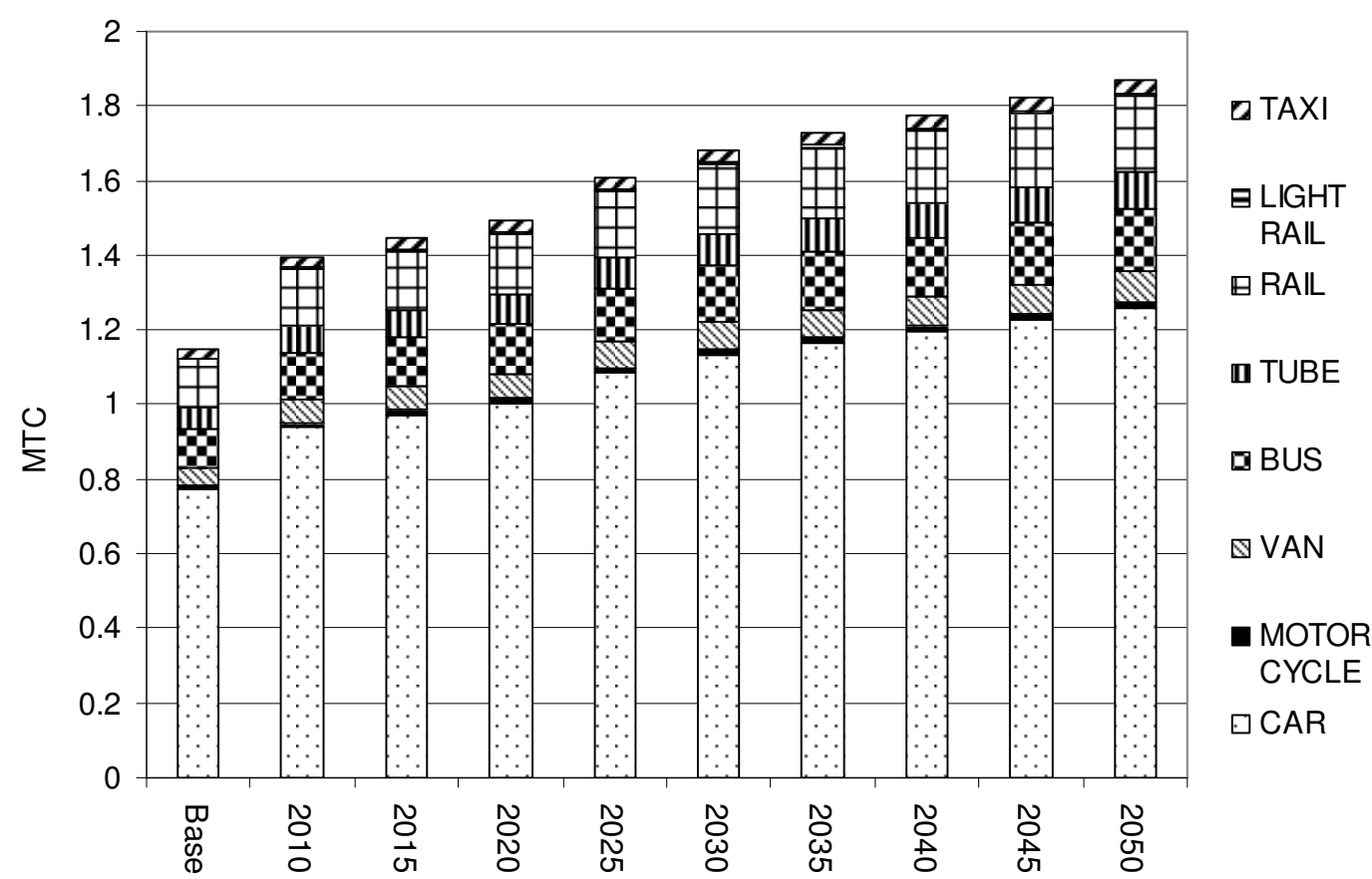

Figure 5: Estimated carbon emissions (million tonnes) within London up to 2050. 


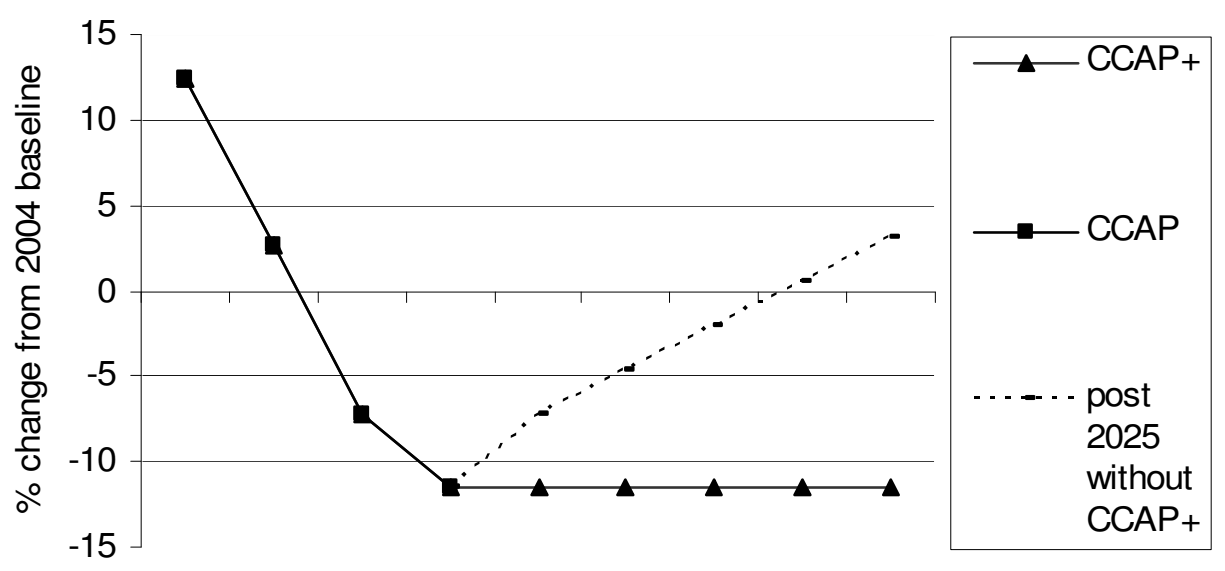

201020152020202520302035204020452050

Figure 6: Estimated impact of the CCAP and CCAP+ on carbon emissions from personal land-based transport within London. 


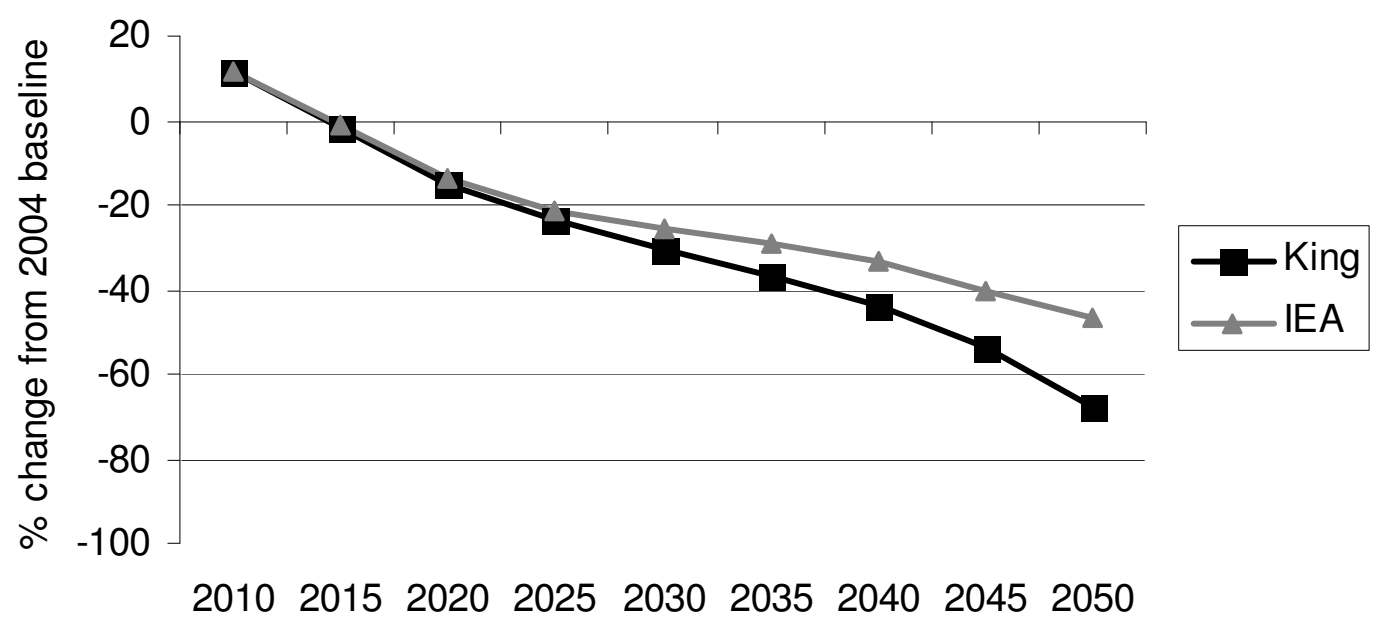

Figure 7: Technology \& CCAP+ scenario 2 - estimated reduction in land-based personal transport carbon emissions within London from 2004 baseline. 


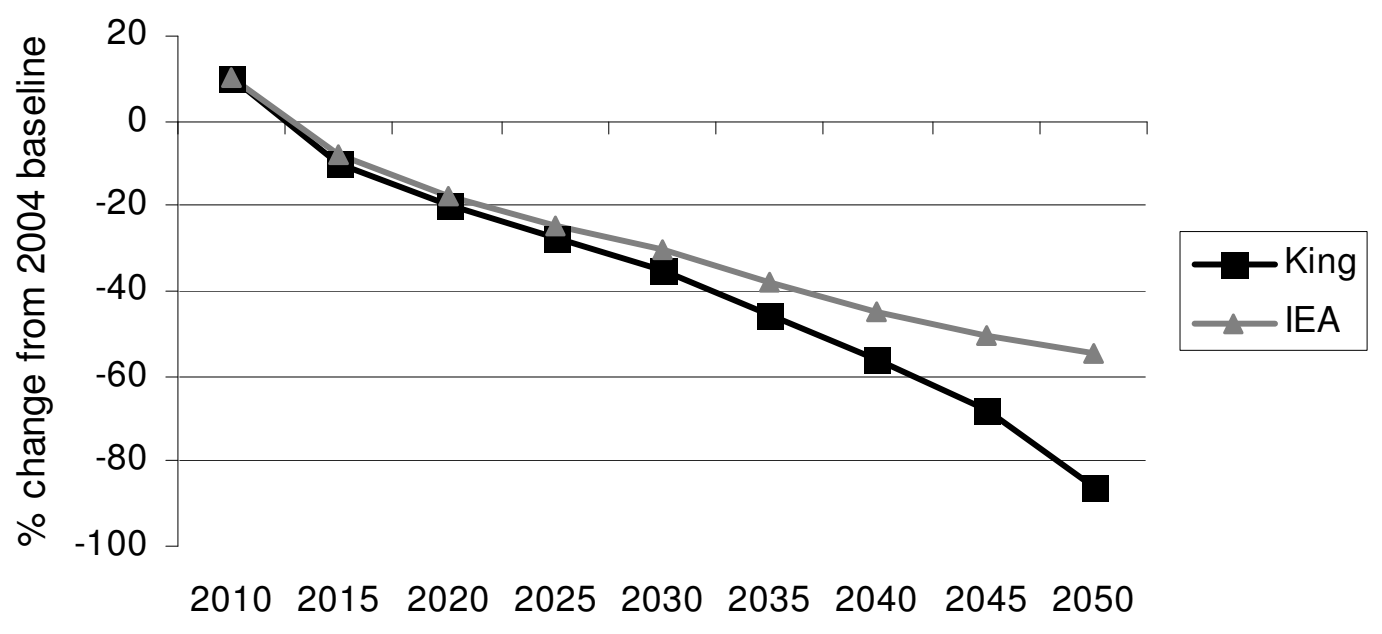

Figure 8: Carbon trading scenario 3 - estimated reduction in land-based personal transport carbon emissions within London from 2004 baseline. 


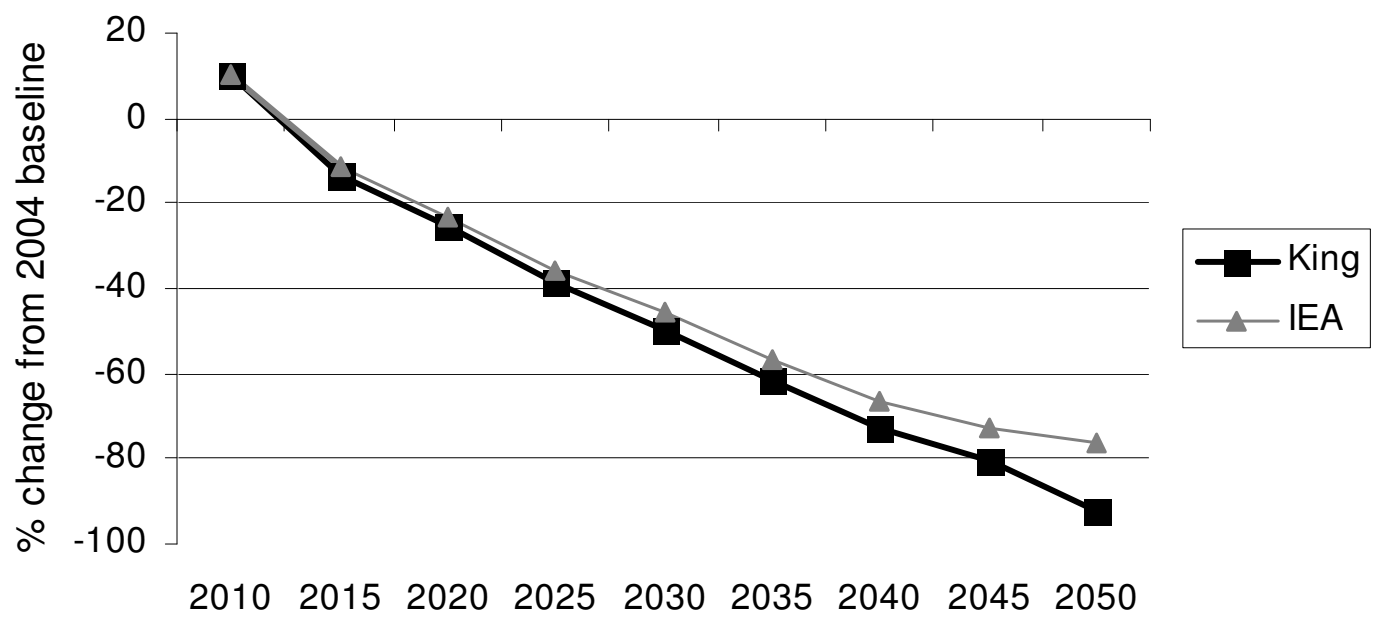

Figure 9: Trading with walking and cycling scenario 4 - estimated reduction in landbased personal transport carbon emissions within London from 2004 baseline. 
Table 1: Kilogrammes of carbon per person per week: London residents

\begin{tabular}{|l|c|c|c|}
\hline & $\begin{array}{c}\text { Inner London } \\
\text { resident }\end{array}$ & $\begin{array}{c}\text { Outer London } \\
\text { resident }\end{array}$ & $\begin{array}{c}\text { All London } \\
\text { residents }\end{array}$ \\
\hline Carbon from all trips & 3.1 & 5.6 & 4.6 \\
\hline $\begin{array}{l}\text { Carbon from all London related } \\
\text { trips (total trip distances) }\end{array}$ & 3 & 4.3 & 3.8 \\
\hline Carbon from all distance travelled & 2.2 & 2.8 & 2.6 \\
\hline within London & & & \\
\hline
\end{tabular}


Table 2: Estimated mode share (\% trips) in 2025 and 2050 for each scenario.

\begin{tabular}{|c|c|c|c|c|c|c|c|c|}
\hline \multirow[t]{2}{*}{ Mode } & \multicolumn{2}{|c|}{$\begin{array}{c}\text { CCAP and } \\
\text { CCAP+ }\end{array}$} & \multicolumn{2}{|c|}{ Technology } & \multicolumn{2}{|c|}{ Carbon trading } & \multicolumn{2}{|c|}{$\begin{array}{c}\text { Walking \& } \\
\text { cycling }\end{array}$} \\
\hline & 2025 & 2050 & 2025 & 2050 & 2025 & 2050 & 2025 & 2050 \\
\hline Car/van & 32 & 30 & 32 & 30 & 28 & 21 & 25 & 5 \\
\hline $\begin{array}{l}\text { Public } \\
\text { transport }\end{array}$ & 41 & 43 & 41 & 43 & 43 & 45 & 34 & 35 \\
\hline Walk & 22 & 22 & 22 & 22 & 23 & 24 & 25 & 26 \\
\hline Cycle & 5 & 5 & 5 & 5 & 6 & 10 & 16 & 34 \\
\hline
\end{tabular}

